\title{
Imagens de mundos de jogo e práticas espaciais ${ }^{1}$ Gameworld images and spatial practices
}

Suely Fragoso ${ }^{2}$

Mariana Amaro ${ }^{3}$

Fabiana Freitas 4

\footnotetext{
${ }^{1}$ Versão revisada e ampliada do trabalho apresentado no congresso anual da Digital Games Research Association (Digra), em Kyoto, Japão, agosto de 2019. Fontes de financiamento: Conselho Nacional de Desenvolvimento Científico e Tecnológico (CNPq) e Coordenação de Aperfeiçoamento de Pessoal de Nível Superior (Capes).

2 Pesquisadora CNPq Nível 1D e professora titular-livre da Universidade Federal do Rio Grande do Sul (UFRGS), onde atua nos cursos de pósgraduação em Comunicação (PPGCom) e graduação em Publicidade e Propaganda e Relações Públicas. Contato: suelyfragoso@ufrgs.br

${ }_{3}^{3}$ Doutoranda do PPGCom da UFRGS. Contato: mari.amaroc@gmail.com

${ }^{4}$ Doutoranda do PPGCom da UFRGS. Contato: frrfreitas@gmail.com
} 
Resumo: Este artigo aborda o impacto das imagens dos mundos de jogo sobre as práticas espaciais dos jogadores. Inicia lembrando que as imagens não são ingênuas e passa à revisão da literatura sobre a carga ideológica de dois tipos de imagens comuns em jogos digitais: mapas e projeções em perspectiva. Considerações sobre o papel mediador das imagens dos mundos de jogo destacam a interdependência das práticas espaciais conhecidas como mapeamento e percurso. Mapas e perspectiva reificam os valores e crenças Modernos, mas sua ocorrência conjunta destaca o hibridismo da experiência espacial. Nos games, esse potencial é intensificado pela aparente liberdade de controle do ponto de vista.

Palavras-chave: representações espaciais; jogos digitais; games; perspectiva; mapa.

Abstract: This article addresses the impact of gameworld images on players' spatial practices. It begins with a reminder that images are not naïve, followed by a review of the literature about the ideological charge of two common image types in games: maps and perspective projections. Considerations about the mediating role of gameworld images highlight the interdependency of spatial practices known as mapping and touring. Maps and perspective reify modern values and beliefs, but their joint occurrence highlights the hybridism of spatial experience. In the case of games, this potential is intensified by the apparent freedom of controlling the point of view.

Keywords: spatial representations; digital games; perspective; map. 


\section{Introdução}

Neste artigo, abordamos questões relativas a dois tipos de enunciação visual encontradas em jogos digitais: mapas e projeções em perspectiva. Nosso olhar se volta para o modo como os mapas e as projeções em perspectiva interferem no conhecimento sobre os espaços dos games 5 e como elas posicionam os jogadores em relação aos mundos de jogo. Assim, o foco de atenção recai sobre as cargas ideológicas próprias daquelas formas de visualização do mundo do jogo e suas implicações. Certas convenções, que serão discutidas ao longo do texto, fazem com que os mapas e as projeções perspectivas sejam considerados retratos fiéis do espaço físico. Por extensão, quando encontradas em ambientes digitais, essas imagens tendem a criar a ilusão de que os mundos de jogo estariam sendo visualizados "como se fossem reais". Nos dois casos, a literatura aponta para a necessidade de atenção ao fato de que os mapas e imagens em perspectiva não são reproduções que refletem ingenuamente o espaço físico, mas construções culturais que fazem proposições sobre ele (DODGE; KITCHIN; PERKINS, 2011). Quando usados para enunciar modelos digitais, mapas e projeções perspectivas impõem a eles essas mesmas proposições, tornando oportuna uma retomada do que já é sabido a respeito dos valores e crenças inscritos naquelas formas de representação visual. Por outro lado, a intenção deste artigo é abordar os diferenciais introduzidos na questão pelo caráter digital das imagens, bem como pela situação de jogo. A observação de exemplos de games aponta para a frequente presença de ambos, mapas e representações em perspectiva, em um mesmo game. As peculiaridades dessa composição, bem como do contexto em que ela ocorre, encaminham a discussão para a presença combinada de mapas e representações em perspectiva, que ao longo do texto toma a frente como ponto central da problematização da apreensão dos espaços dos mundos de jogo.

Para encaminhar essa discussão, lançamos mão da literatura que trata especificamente do caráter mediador das imagens (COUCHOT, 1993; MACHADO, 1984, 1990; PANOFSKY, 1997; QUÉAU, 1993); da bibliografia que relaciona representação, domínio e poder no campo da geografia (como DODGE; KITCHIN; PERKINS, 2011; HARLEY, 1989; ROSE-REDWOOD, 2015; THRIFT, 1996) e, ainda, dos textos oriundos dos estudos de jogos (AARSETH, 1998; CALLEJA, 2011; JØRGENSEN, 2013; NITSCHE, 2008). Alguns autores dessa última frente de estudos destacaram a potência da noção de "geografias de ação" e suas derivações

${ }_{5}^{5}$ Este uso das palavras game e videogame como sinônimo de “jogo digital” já foi incorporado aos dicionários de língua portuguesa. 
(DE CERTEAU, 1998) para a discussão do status ontológico dos mundos de jogo e das possibilidades e requisitos da jogabilidade (GOLDING, 2013; SCULLYBLAKER, 2014). Entre eles, destacamos os trabalhos de Lammes e seus coautores (LAMMES 2008, 2009; LAMMES; VERHOEFF, 2008; LAMMES; WILMOTT, 2016), para quem a presença de mapas em jogos digitais promove a hibridação de dois tipos de práticas espaciais, conhecidas como "mapeamento" e "percurso"6 (DE CERTEAU, 1998; LINDE; LABOV, 1975). Diferentemente da equipe liderada por Lammes, entendemos que a percepção do mapeamento e do percurso como categorias independentes é uma distorção, um reflexo dos dualismos modernos ${ }^{7}$. Por esse motivo, propomos uma variação daquela hipótese: para nós, os jogos não hibridizam o "mapeamento" e o "percurso", mas destacam sua interdependência, ou seja, chamam a atenção para um hibridismo que nunca deixou de estar presente. Ao ampliar o escopo da questão para abranger também as projeções em perspectiva, estamos aderindo a um paralelismo que já havia sido sugerido por de Certeau (1998), que associou o percurso com o ponto de vista do caminhante e o mapeamento com a visualização de uma cidade a partir de pontos de vista muito elevados (por exemplo, do alto do Corcovado, no Rio de Janeiro; ou do edifício Itália, em São Paulo). Outro diferencial do trabalho que apresentamos decorre de aspectos específicos de nosso objeto de análise: enquanto De Certeau (1998) se preocupava com as práticas cotidianas, nosso foco são as imagens encontradas em jogos digitais. Essa mudança traz à tona questões relativas às qualidades gráficas dessas imagens, ao modo como mapas e imagens em perspectiva são apresentados ao jogador e, ainda, às especificidades dos próprios jogos, como as variações na mobilidade e a possibilidade de controle do ponto de vista.

\section{Imaginando o mundo}

O primeiro passo para uma discussão do uso de mapas e imagens em perspectiva para representação visual de mundos de jogo consiste em conceituar e

\footnotetext{
${ }^{6}$ Essas categorias são normalmente traduzidas para a língua portuguesa como "mapa" e "percurso", nomenclatura que poderia ser considerada mais fiel tanto a map e tour, encontradas em Linde e Labov (1975), quanto a carte e parcour, utilizadas por de Certeau (1993). Nossa opção por "mapeamento" deve-se à necessidade de diferenciar a prática espacial da enunciação visual do tipo mapa.

${ }^{7}$ Seguimos a concepção sociológica segundo a qual a Modernidade é marcada pela valorização do pensamento científico (racionalidade) em detrimento das crenças religiosas e místicas, como discutido, entre outros, por Weber (2012). Essa diferenciação implica, ainda, a valorização da objetividade, da ideia de verdade e da individualidade. Em termos mais gerais, trata-se de um período caracterizado por formulações analíticas e dualistas, como a separação entre a natureza e a cultura, a ciência e a política, o real e o ficcional, entre outros (LATOUR, 1991).
} 
diferenciar essas duas formas de enunciação. Séculos de direcionamento de nossa percepção para as diferenças tendem a obscurecer o que os mapas e as imagens em perspectiva têm em comum, a começar pela intenção de representar o espaço 3D em superfícies 2D com a maior precisão possível. Para isso, recorrem aos mesmos princípios, tendo como base a geometria euclidiana. Também nos dois casos, o referente pode ser físico (como, respectivamente, na cartografia e fotografia) ou fictício (por exemplo em ilustrações, pinturas e na computação gráfica).

Por convenção, reservamos neste texto a palavra "mapa” para designar projeções perpendiculares, ou seja, especialmente aquelas utilizadas para transmitir informação geográfica. Alternativamente, em certas passagens usamos a expressão “imagens cartográficas”. Já as projeções perspectivadas são caracterizadas pela possibilidade de identificar e posicionar o ponto de vista a partir do qual a imagem se organiza. Assim definida, a categoria "perspectiva” abrange diversas variações, como a perspectiva central e as projeções oblíquas. Entre as imagens em perspectiva mais disseminadas estão as imagens técnicas geradas com câmeras, que abrangem a fotografia, o cinema e a televisão. Deriva dessas imagens a figura da "câmera virtual", graças à qual a perspectiva central foi associada à ideia de realismo na computação gráfica em geral (FRAGOSO, 1992) e, por extensão, nos games.

Em prol da clareza do texto e fluxo de leitura, utilizamos o substantivo representação em referência às imagens em perspectiva e aos mapas, bem como o verbo representar para designar a relação que eles estabelecem com seus referentes. Com isso, não estamos abraçando uma perspectiva ingênua segundo a qual essas imagens poderiam substituir seus referentes de forma objetiva e suficiente: uma premissa básica deste texto é justamente que isso não ocorre. Por outro lado, nem mesmo as chamadas "teorias não representacionais" descartam o uso dessas palavras ou mesmo negam que as representações existem e são relevantes. Muito ao contrário: elas reconhecem e enfatizam sua existência, sua importância cognitiva e material e sua agência sociocultural. Conforme os autores vinculados àquela corrente, as teorias não representacionais consideram que as representações visuais são "parte de um processo mais amplo de conhecimento" e enfatizam que elas estão sempre "solidamente incorporadas em um processo de negociação social contextualmente específico” (THRIFT, 1996, p. 8, tradução nossa). Seguimos pelo mesmo caminho

${ }^{8}$ A "câmera virtual" corresponde ao ponto de vista a partir do qual é realizada a renderização dos modelos digitais tridimensionais. 
ao apontarmos as forças de naturalização que, ao longo de séculos, atribuíram aos mapas e às projeções perspectivadas uma pretensão de objetividade e completude.

Uma vez estabelecido que toda representação, verbal ou visual, é necessariamente insuficiente e ideologicamente motivada, a distância entre imagens e a realidade pode ser compreendida em vários níveis. O mais superficial e mais fácil de perceber abriga aspectos gráficos como iluminação e cores. Já as conotações são dependentes de contexto e, portanto, mais sutis. Crenças e convicções muito disseminadas e vigentes ao longo de séculos, como as que nos interessam neste artigo, são particularmente difíceis de identificar, sobretudo quando inscritas na estrutura da enunciação. Na próxima seção, revisitamos brevemente a literatura anterior a esse respeito.

\section{Mapas e perspectivas}

Dodge, Kitchin e Perkins (2011, p. 13, tradução nossa) afirmam que a carga ideológica dos mapas "faz parte de sua composição e construção, sua autoapresentação e design, seu conjunto de símbolos e categorização, suas legendas e discursos de apoio". Apesar disso, os mapas têm a pretensão de serem espelhos do espaço físico: apenas quando submetidos à dúvida revelam-se como desenhos geométricos abstratos. Essa constatação é o ponto de partida do texto paradigmático em que Harley (1989) se propôs a refutar “a crença ilusória de que o mapa poderia fornecer uma janela 'transparente' ao mundo, desde que as representações cartográficas correspondessem ou espelhassem 'com precisão' os fenômenos que alegam representar" (ROSE-REDWOOD, 2015, p. 2, tradução nossa).

As mesmas observações são válidas para as imagens em perspectiva, em relação às quais a mesma metáfora da "janela transparente" é utilizada com frequência ainda maior. No entanto, projeções perspectivadas não são menos artificiais que os mapas e, assim como eles, estão à disposição das crenças e valores materializados em sua estratégia de codificação. Esse ponto foi destacado em um clássico sobre o assunto, Perspective as symbolic form (A perspectiva como forma simbólica) (PANOFSKY, 1997), lançado originalmente em 1927. Nessa obra, Panofsky desafiou a correspondência entre a perspectivação e o olhar humano argumentando, entre outras coisas, que as perspectiva central se organiza em torno de um ponto único e fixo, enquanto a visão humana constrói a profundidade nas superfícies côncavas do interior de dois olhos que são paralelos e estão permanentemente em movimento. Mesmo quando se busca alguma forma de compensação desses fatores, como nos estereoscópios ou no cinema 3D, a perspectivação ainda leva em conta apenas 
os aspectos geométricos da formação da imagem na retina, deixando de lado os fatores psicofisiológicos da apreensão espacial (FRAGOSO, 2003, 2004, 2005; MACHADO, 1984;).

A partir da constatação de que o espaço que a perspectiva materializa é infinito, imutável e homogêneo, pode-se dizer que seus princípios são afinados com as ideias da Revolução Copérnica (REES, 1980). É também um espaço antropocêntrico, que se organiza em torno do ponto de vista e em função dele. Ao mesmo tempo, é também um espaço afinado com a subjetividade cartesiana, uma vez que o ponto de vista é externo à imagem. Em outras palavras, o ponto de vista é uma analogia a um olho que observa, porém não faz parte do mundo que ele vê. Esse olho determinador, que é um ponto geométrico em torno do qual a imagem se organiza, é hierarquicamente superior ao olho humano que visualiza a imagem, pois define de onde a cena é observada e em que condições a observação ocorre. Desse modo, o que a imagem em perspectiva oferece é apenas uma paisagem que já foi olhada e já se encontra dominada por um outro olhar, que dirige o nosso (MACHADO, 2005).

Essa predeterminação é mais evidente nos mapas, mesmo porque sua intenção não é corresponder à visão humana, mas à realidade física. Apesar dessa diferença, os mapas e as projeções em perspectiva têm muito em comum. Ambos são visões objetivadas, a partir de pontos externos: no caso dos mapas, o ponto de vista é tão externo que não é sequer possível determinar sua localização. Do mesmo modo que a perspectiva, os mapas também pressupõem um espaço copernicano, infinito e homogêneo. Além disso, nos mapas, as posições relativas e as hierarquias inerentes às diversas localizações são menosprezadas em prol da equiparação dos valores de todos os lugares (REES, 1980).

Ao cunhar a frase "o mapa não é o território", Korzybski (1958) utilizava a palavra "mapa" como metonímia para todas as criações humanas e formas de expressão. Não há impedimento, entretanto, para entender literalmente sua afirmação de que "independente do que se proponha a mapear, todo mapa é, no mínimo, um mapa de seu próprio criador; um reflexo de suas pressuposições, talentos, visões de mundo, etc." (1958, p. xvii, tradução nossa). Em uma apropriação mais direcionada daquela ideia, Borges (1999) traça a alegoria entre mapa e território para apontar o modo como o conhecimento científico da Modernidade depende do apagamento dos recortes e distorções para preservar a aparência de objetividade e precisão de seus modelos. 
De fato, a própria diferenciação entre mapas e projeções perspectivadas é uma construção moderna. Até o Renascimento, a pintura de paisagens e a criação de mapas não eram atividades separadas e não havia sequer uma terminologia para distingui-las (REES, 1980, p. 60). Apesar disso, os pontos em comum entre as imagens em perspectiva e os mapas continuam excluídos tanto nos estudos críticos de cartografia (DODGE; KITCHIN; PERKINS, 2011 ; REES 1980) quanto nas discussões orientadas pela arte e comunicação visual (MACHADO, 1984; PANOFSKY, 1997). É possível que isso se deva à reivindicação em separado dessas técnicas de representação pela ciência e pela arte que remonta à leitura renascentista da diferenciação realizada por Ptolomeu, que propôs a existência de "duas linguagens cartográficas [...] a matemática e a pictórica, típicas de dois ramos diferentes de representação do mundo: a Geografia e a Corografia” (NUTI, 1994, p. 117 , tradução nossa). A geografia é associada com a representação topográfica, e a corografia daria conta das características sociais e culturais. Enquanto os mapas da geografia foram associados à representação topográfica, a corografia voltou-se para a representação das características sociais e culturais, identificando-se com a pintura de paisagens e com as descrições verbais de territórios e lugares. No caso dos mapas, essa dissociação corresponde à contínua elevação do ponto de vista, que alcança o nível máximo de abstração quando se torna perpendicular ao solo. Até o século XVII, no entanto, eram mais frequentes as formas híbridas, que combinavam princípios de cartografia e perspectivação compondo um formato específico de mapa, que Nuti (1994) denominou "plano perspectivo". A Figura 1 aponta a similaridade entre os planos perspectivos do período renascentista e os games conhecidos como God view.

Essas convergências não significam que as imagens em perspectiva, os planos perspectivos e os mapas são equivalentes. No caso dos games, a frequente combinação de mapas e imagens em perspectiva tende a ser justificada de forma simplista, por exemplo por atribuição de “insuficiência” à perspectiva, que precisaria ser suplementada com imagens bidimensionais, que são mais esquemáticas (AARSETH, 2001, p. 157). 


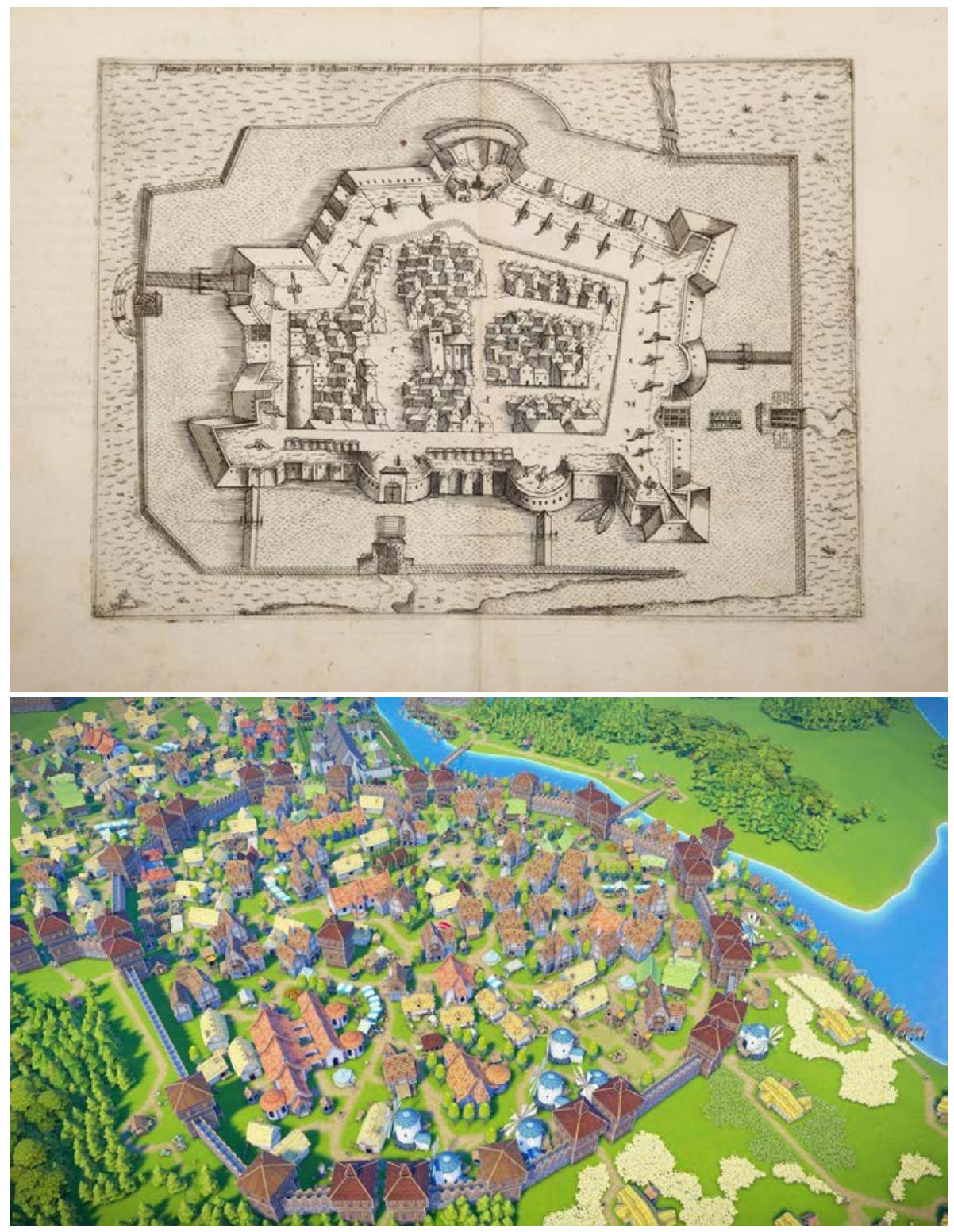

Figura 1: No alto, mapa da cidade de Wittenberg. Paolo Forlani, 1567. Embaixo, visualização de tela do jogo Foundation, por Raptor, 2019.

Fonte: Libreria Antiquarius e Foundation (Polymorph Games, 2019)9 .

\footnotetext{
${ }^{9}$ Disponíveis respectivamente em: https://bit.ly/2Hwtvcy e https://youtu.be/73-uPKWbAyA. Acesso em: 24 fev. 2020.
} 
Entretanto, não é verdade que os mapas sejam mais precisos ou mais completos que outros tipos de projeções. O benefício de seu uso combinado advém justamente do fato de que diferentes estratégias de enunciação revelam e escondem aspectos diferentes dos espaços que representam. Além disso, posiciona o jogador de uma maneira diferente em relação ao mundo: a vista vertical assegura mais precisão, controle e autonomia ao indicar ao jogador que ele transcende o mundo do jogo. Nos jogos em terceira pessoa, o posicionamento externo do ponto de vista remove o jogador da linha de ação: ainda que o comande, o jogador ocupa a posição de observador em relação ao avatar. Já os jogos em primeira pessoa forçam o alinhamento entre o ponto de vista e o campo de visão do jogador (Figura 2). A intenção é aumentar o sentimento de presença no mundo do jogo, porém essa estratégia pode causar estranheza e tende a aumentar as possibilidades de ruptura da experiência de jogo (FRAGOSO, 2014) devido às imprecisões inerentes à imposição de correspondência entre a visão do jogador e o "olho simbólico" da perspectiva.
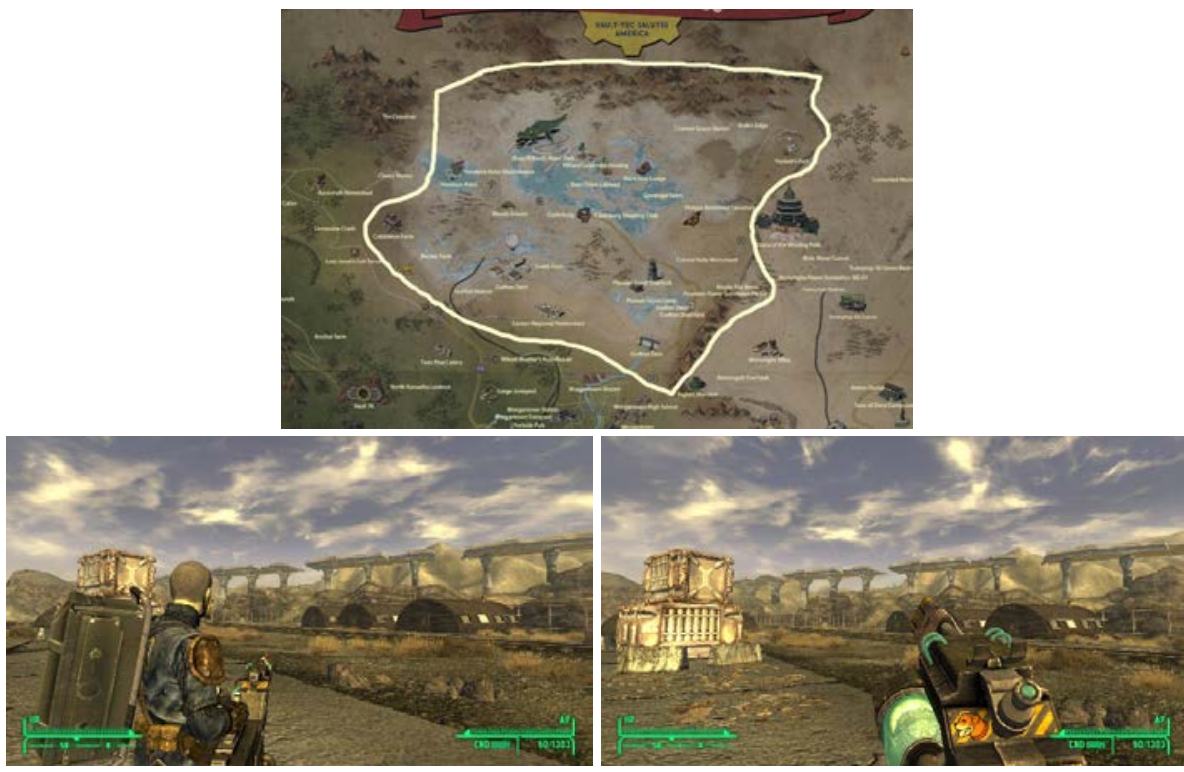

Figura 2: No alto, uso de mapa em jogo digital. Embaixo, à esquerda, uso da perspectiva central com ponto de vista em terceira pessoa e à direita, perspectiva central em primeira pessoa em Fallout New Vegas.

Fonte: Fallout New Vegas (Obsidian Entertainment e Bethesda Softworks, 2010).

Outras particularidades do uso de mapas e perspectivações em games serão discutidas a seguir, iniciando pelas questões relacionadas ao caráter digital dessas imagens. 


\section{Imaginando mundos de jogo}

Neste artigo, optamos por direcionar nossa atenção aos games com mundos tridimensionais imaginários, ou seja, cujas imagens são geradas diretamente no computador. Atualmente, o convívio com esse tipo de imagem já se encontra tão naturalizado que as implicações de suas diferenças em relação a outras imagens técnicas tendem a passar despercebidas. Por isso mesmo, é importante destacar as percepções dos autores que discutiram a modelagem digital em seus primeiros anos, como Machado (1990), Fragoso (1992) e Couchot (1993), para quem o papel mediador das imagens digitais seria ainda mais intenso justamente devido à inexistência de referentes materiais. Queáu (1993, p. 93-94) atribuiu essa intensificação a três fatores: a natureza "essencialmente abstrata" dessas imagens, a possibilidade de geração em tempo real e a capacidade de interação com as enunciações.

Os três fatores apontados por Queáu se aplicam às imagens do próprio mundo do jogo, mas não às imagens do mundo que habitamos. Isso demarca a diferença entre os mapas e as imagens em perspectiva que encontramos no cotidiano e nos games: nos dois casos, os mapas são sempre compreendidos como representações a serem cotejadas com o mundo conhecido "em primeira mão". Por essa razão, a analogia entre os mapas em games e em outros sistemas digitais é direta (Figura 3). $\mathrm{O}$ mesmo se aplica às imagens em perspectiva encontradas no cotidiano, por exemplo na pintura, no cinema e na televisão. Nos games, entretanto, as imagens em perspectiva são apresentadas como se correspondessem à experiência espacial mediada apenas pela visão ${ }^{10}$. Em outras palavras, enquanto uma imagem em perspectiva encontrada no cotidiano é compreendida como uma enunciação de um espaço que também pode ser visto “em primeira mão”, uma imagem do mundo de jogo é a experiência mais imediata possível, apesar de ser uma representação em perspectiva. Uma vez que o mundo do jogo só pode ser visto sob essa forma de codificação, todo o conhecimento sobre ele é, sempre e necessariamente, carregado com os princípios, valores e crenças inscritos na perspectivação.

Ao discutir as enunciações do mundo do jogo, os autores dos estudos de (FRAGOSO; AMARO, 2018) tendem a privilegiar as questões relativas ao envolvimento espacial dos jogadores durante o gameplay (por exemplo, CALLEJA, 2011; JØRGENSEN, 2013). A única referência que talvez se aproxime de nossa opção pelo foco no caráter mediador dessas imagens seria o trabalho de

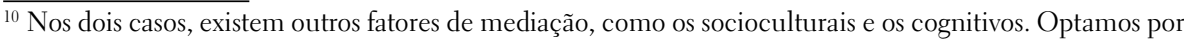
não mencioná-los neste ponto da discussão para não comprometer a clareza do texto.
} 
Nitsche (2008, p. 77, tradução nossa), que reconhece que as câmeras realizam recortes, seleções e interpretações que "carregam o mundo virtual com uma perspectiva". Nessa passagem, a palavra "perspectiva” tem duplo sentido: refere-se à lógica estrutural de acordo com a qual essas imagens são criadas e também aos valores e crenças inerentes àquela lógica.

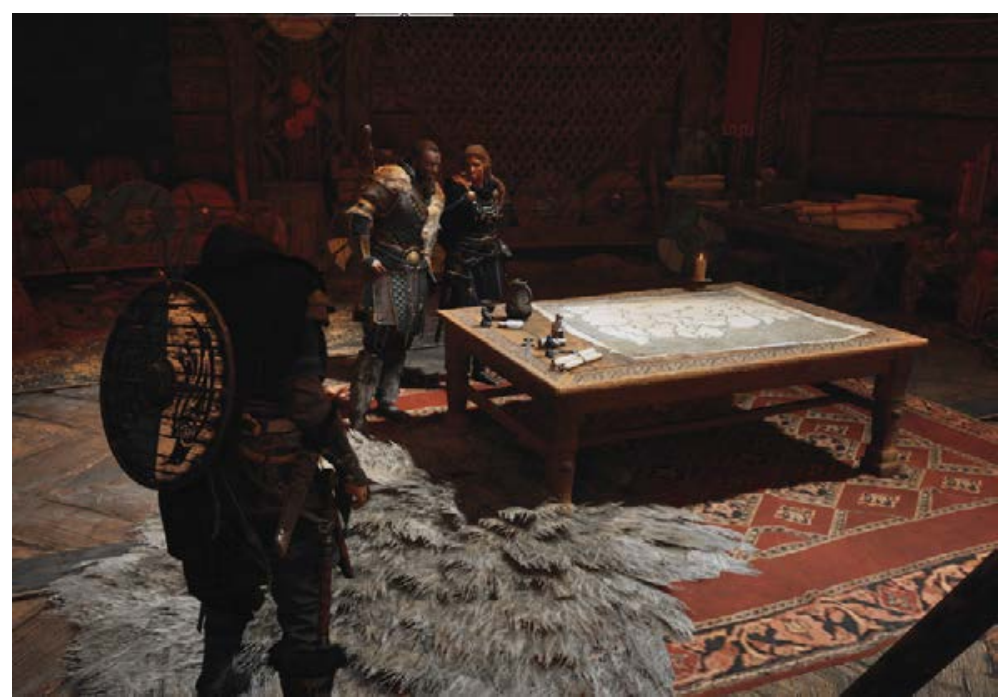

Figura 3: Mapa intradiegético em Assassin's Creed Valhalla.

Fonte: Assassin's Creed Valhalla (Ubisoft, 2020).

Esses valores e crenças são reificados pela disseminação de imagens produzidas por câmeras, como na fotografia, cinema e televisão (MACHADO, 1984, 1990). Essa reificação é ainda mais intensa no caso dos games, pois as câmeras virtuais não recortam e interpretam o espaço físico, mas materializam modelos tridimensionais criados a partir da perspectiva moderna, ou seja, que correspondem a um espaço que antes mesmo de sua enunciação já é matemático, infinito e homogêneo, concebido de acordo com os princípios da revolução copernicana (FRAGOSO, 2003 2005).

Graças ao uso da perspectiva e à mobilidade do ponto de vista, não é raro encontrar comparações entre a narrativa em jogos e no cinema (LAMMES; VERHOEFF, 2008; NITSCHE, 2008). Entretanto, as diferenças entre as estratégias narrativas do cinema e dos games são, no mínimo, tão importantes quanto suas similaridades (KING; KRZYWINSKA, 2002). Essas diferenças devem-se, sobretudo, ao fato de que os mundos dos jogos digitais não são criados para serem vistos, mas para 
serem explorados. Para isso, é preciso que a câmera virtual (ou seja, o ponto de vista) esteja, pelo menos até certo ponto, sob controle do jogador (Figura 4).

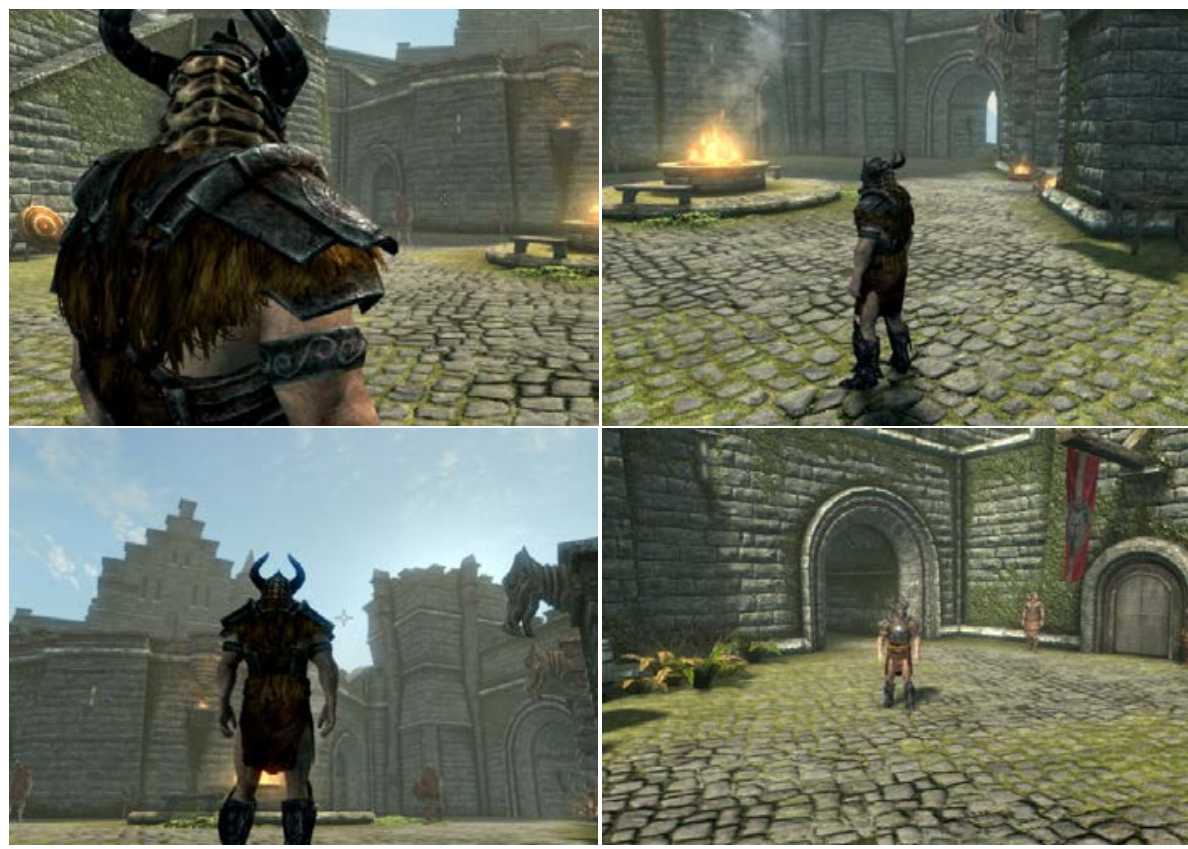

Figura 4: Variações da câmera virtual sem que o personagem esteja em movimento em Elder Scrolls V: Skyrim.

Fonte: Elder Scrolls V: Skyrim (Bethesda, 2011). Capturas de tela cedidas para as autoras por Natan Kussler, 2020.

Esse fator demarca mudanças no papel do público para o qual as imagens das câmeras físicas e virtuais são produzidas: enquanto, no cinema, o público é posicionado como voyeur (MACHADO, 1990, 1997), os jogos digitais demandam que o jogador assuma a atitude de um explorador. Lammes e Verhoeff (2008) caracterizam a narratividade dos jogos digitais como uma decorrência desse fator: para eles, as narrativas dos games são relatos espaciais, estórias de navegação e descoberta, nas quais o espaço prevalece sobre o tempo. Essa percepção não invalida a necessidade de observar as interdependências entre duas facetas da espacialidade dos games: a arquitetônica (navegável) e a cinemática (narrativa) (NITSCHE, 2008). A similaridade entre essas percepções sobre as narrativas e os mundos de jogo e as descrições das práticas espaciais cotidianas encontradas em de Certeau (1998) serão discutidas na próxima seção. 


\section{Dinâmicas espaciais em games}

Em seu trabalho sobre as práticas cotidianas, de Certeau elenca, de um lado, as diferenças decorrentes da compreensão de que as coisas ocupam um mundo objetivo, externo e inerte, ou seja, um espaço que simplesmente existe, mas não afeta ou altera o que nele está contido. De outro lado, está a percepção das práticas subjetivas que "acordam os objetos" e conferem sentido ao espaço em que eles se encontram. A articulação dessas duas relações com o espaço resulta em "geografias de ação" que podem ser expressas como "relatos espaciais" (DE CERTEAU, 1998, p. 200-203). De Certeau (1998, p. 204) relacionou as duas formas elementares das geografias de ação com as noções de "mapeamento" e "percurso", sendo o mapeamento uma representação estática ("Ao lado da cozinha fica o quarto das meninas") enquanto o percurso é dinâmico ("Você dobra à direita e entra na sala de estar"). Damos preferência, no entanto, à versão mais detalhada dessas duas categorias, encontrada no estudo original de Linde e Labov (1975), que serviu de referência para de Certeau. Naquele trabalho, os autores abordaram as relações entre as formas de apreensão do espaço e sua expressão discursiva a partir de descrições de layouts de apartamentos, tendo chegado às duas categorias mencionadas por de Certeau. Entretanto, para eles, os mapeamentos descrevem relações entre lugares e podem ser visuais ou verbais, enquanto os percursos tanto podem ser estáticos quanto dinâmicos (Tabela 1).

Tabela 1: Descrições de apartamentos dos tipos "mapeamento" (verbal e visual) e "percurso" (estático e dinâmico).

\begin{tabular}{|c|c|c|}
\hline MAPEAMENTO VERBAL & $\begin{array}{c}\text { MAPEAMENTO } \\
\text { VISUAL }\end{array}$ & PERCURSO ESTÁTICO \\
\hline $\begin{array}{l}\text { Eu diria que é um grande quadrado, } \\
\text { dividido em quatro unidades. } \\
\text { Se você estivesse olhando este } \\
\text { apartamento de cima, ele seria, como } \\
\text { eu disse antes, semelhante a um grande } \\
\text { quadrado com duas linhas desenhadas } \\
\text { através do centro para criar quatro } \\
\text { quadrados menores. } \\
\text { Agora, nas pontas - hmn -, nas duas } \\
\text { caixas menores que dão para a rua, você } \\
\text { tem a sala e um quarto. } \\
\text { Entre essas duas caixas você tem um } \\
\text { banheiro. } \\
\text { Agora, entre as próximas duas caixas, } \\
\text { de frente para o quintal, você tem um } \\
\text { pequeno hall e então as duas caixas, } \\
\text { uma delas é um quarto e a outra é a } \\
\text { cozinha e então o pequeno hall - ah - } \\
\text { um pouco depois disso }\end{array}$ & Nole & $\begin{array}{l}\text { A entrada dá para a cozinha. } \\
\text { E através de um arco está a sala. } \\
\text { E depois, através de uma porta } \\
\text { separada, uma porta que fecha, está } \\
\text { o quarto. } \\
\text { Eu diria que o quarto é só um pouco } \\
\text { menor que a sala. } \\
\text { Eu acho que o tamanho é bem bom } \\
\text { para duas pessoas. } \\
\quad \text { PERCURSO DINÂMICO } \\
\text { Você entrou pela porta da frente. } \\
\text { Tinha um hall estreito. } \\
\text { À esquerda, a primeira porta que } \\
\text { você viu era um quarto pequeno. } \\
\text { Então tinha a cozinha, e então o } \\
\text { banheiro, } \\
\text { E então o cômodo principal era no } \\
\text { fundo, a sala, eu diria. }\end{array}$ \\
\hline
\end{tabular}

Fonte: Adaptado de Linde e Labov (1975, p. 927-929). 
Os quatro tipos de representações espaciais podem ser encontrados em jogos que privilegiam a enunciação verbal, como os role-playing games (RPG) on-line que eram populares nos anos 1980-90 (Figura 5).
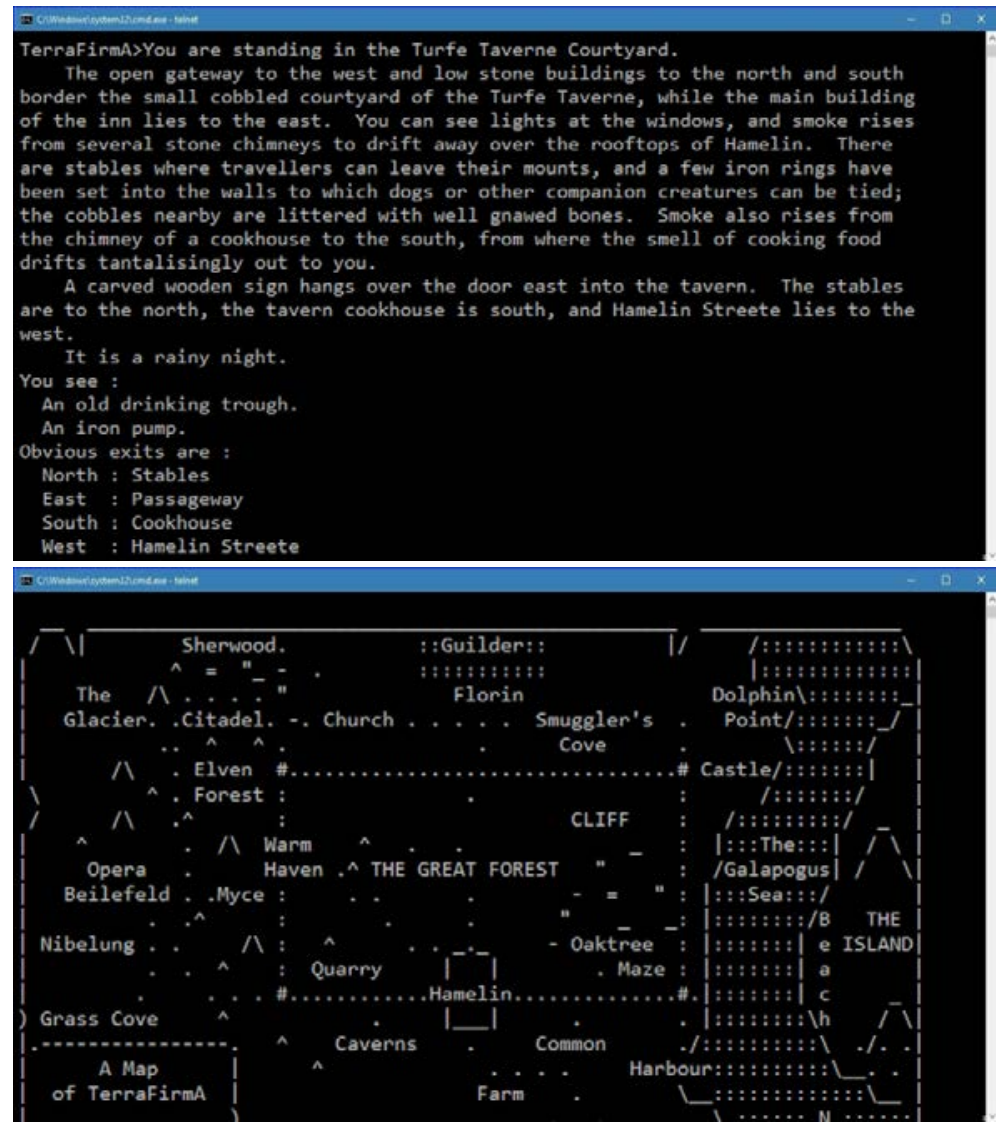

Figura 5: representações espaciais na MUD TerraFirmA. No alto, pátio da Taverna Turfe. Embaixo, parte da representação visual identificada como "mapa" pelo próprio jogo.

Fonte: Captura de tela realizada por Suely Fragoso, 2019.

De Certeau (1998) destaca a artificialidade da dissociação entre mapeamentos e percursos, que ocorre para acomodar a estrutura dualista do pensamento moderno. Como exemplo, o autor menciona a forma híbrida dos mapas medievais constituídos de traçados retilíneos, e indicações de "etapas a efetuar (cidades onde passar, parar, alojar-se, rezar etc.) e distâncias computadas em horas ou em dias, ou seja, em tempos de marcha” (DE CERTEAU, 1998, p. 205, tradução nossa). A Figura 6 assinala a semelhança entre esse tipo de mapa e enunciações encontradas em games. 


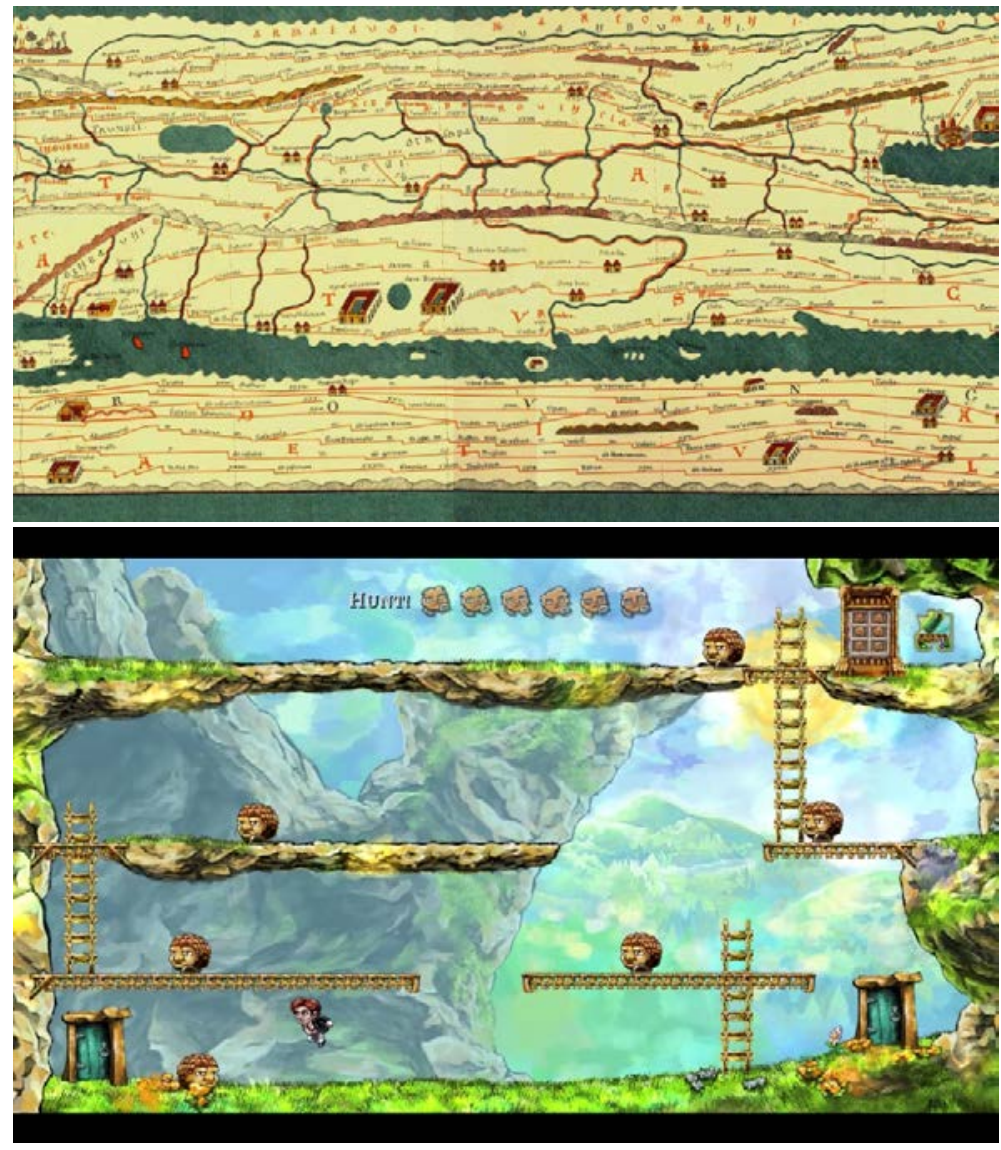

Figura 6: No alto, Tabula Peutingeriana, séc. I-IV (detalhe de fac-símile elaborado por Konrad Miller, 1888). Embaixo, tela do jogo Braid (Hothead Games / Number None, 2008).

Fonte: Wikimedia Commons e Braid (Hothead Games/Number None, 2008). Captura de tela realizada por Mariana Amaro, 2020.

Com a passagem para a cartografia moderna, as marcas dos percursos foram progressivamente apagadas em privilégio das enunciações do tipo mapa. Entre os testemunhos das fases intermediárias desse processo estão as ilustrações encontradas nas cartas náuticas produzidas entre os séculos XV e XVII. Essas imagens, que não têm função decorativa, correspondem a "fragmentos de histórias", registros dos eventos e "operações - de viagem, guerreiras, construtoras, políticas ou comerciais - que possibilitam a fabricação de um plano geográfico” (DE CERTEAU, 1998, p. 206). A presença dessas ilustrações constrói formas híbridas de mapeamento e percurso, que acomodam com facilidade nosso conhecimento da cartografia moderna e nossa experiência espacial cotidiana. Sua presença nos games demarca a temporalidade 
do mundo do jogo (são mapas "antigos") e situa o jogador como um explorador que se aventura em mundos desconhecidos. No exemplo da Figura 7, o mapa do jogo combina o hibridismo dos mapas ilustrados a outra forma de enunciação característica do mesmo período: o plano perspectivo (NUTI, 1994). Compõe-se assim um duplo hibridismo, uma vez que as representações oblíquas combinam a suposta objetividade do ponto de vista vertical do mapa e a subjetividade da experiência cotidiana.

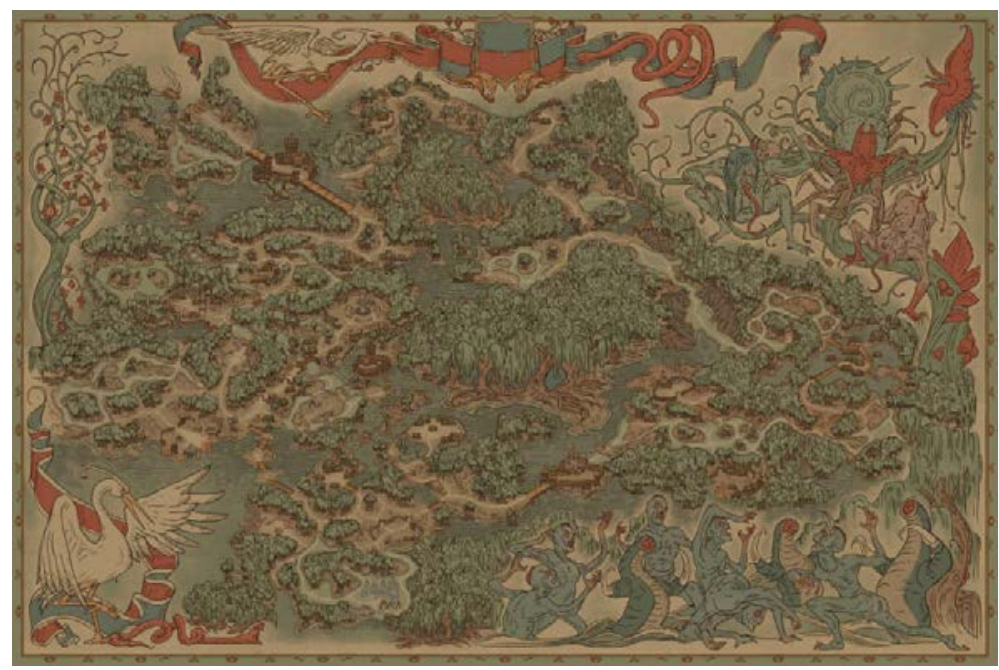

Figura 7: Mapa do jogo Thronebreaker.

Fonte: Thronebreaker (CD Projekt RED, 2019), por Yama Orce, 2018.

A adequação da estrutura dual das geografias de ação ao estudo das enunciações espaciais em games foi apontada por autores anteriores que, no entanto, quase sempre privilegiaram uma visão binária ao associar o "percurso" com a navegação do jogador e o "mapeamento" com as enunciações objetivas do espaço dos jogos (por exemplo: EGLISTON, 2015; SCULLY-BLAKER, 2014). Uma exceção seria o trabalho de Golding (2013), que retoma o paralelo entre mapeamento e percurso e as noções de "estratégia” e "tática” apresentadas por De Certeau (1998). Resumidamente, pode-se dizer que as estratégias são práticas racionalizadas através das quais certos sujeitos ou grupos estabelecem e reificam sua posição de poder em relação aos outros. Para tanto, realizam um "gesto Cartesiano" e, portanto, Moderno, que enfatiza a distinção entre o que lhes é próprio em oposição a uma exterioridade de alvos ou ameaças. As táticas, por sua vez, são "a arte do fraco", constituída por ações distribuídas que visam estabelecer as condições necessárias à autonomia (DE CERTEAU, 1998, p. 99-101). Golding transpôs a percepção da visão estratégica 
de uma cidade de um lugar alto e a experiência tática de andar nas ruas de Certeau (1998, p. 169-171) para sua experiência com games nos seguintes termos:

Em Assassin's Creed II o conhecimento que meu personagem tem do ambiente onde se encontra e sua eficácia em encontrar tarefas, aperfeiçoamentos e outros lugares desejáveis está diretamente vinculada a quantos prédios altos eu encontro para ele escalar. Olhar a partir de cima é ver em conceitos, e ver em termosdeconhecimento, podereinfluência.(GOLDING,2013, p. 28, tradução nossa)

Pontos de vista elevados aumentam o conhecimento e o controle sobre o espaço, mas cobram seu preço em distanciamento e desapego. Golding (2013) reconhece isso em seu comentário de que os jogadores nunca podem ter uma perspectiva panorâmica e holística como a das estratégias descritas por de Certeau (1988), uma vez que, no caso de jogos, o domínio dos caminhos alternativos permanece sempre na mão dos designers. Concordamos que a comparação entre jogadores e cartógrafos, encontrada em autores como Friedman (1998), é falha, porém não porque o mundo do jogo seja desconhecido e as opções não estejam disponíveis para o jogador. Afinal, essa situação é análoga à dos primeiros navegadores, que também desconheciam as regiões que exploravam e progrediam mapeando e navegando ao mesmo tempo. Por outro lado, a analogia entre o jogador e o explorador, ou mesmo a ideia do jogador como um “cartógrafo a passeio”(LAMMES, 2008, 2009, 2016; LAMMES; VERHOEFF, 2008), ainda deixa de levar em conta as implicações das diferenças ontológicas entre o espaço do jogo e o espaço físico. Uma dessas diferenças está na base dos questionamentos que levantamos neste artigo: ao contrário da experiência da vida cotidiana, a experiência espacial dos jogadores é necessariamente mediada por enunciações cuja carga ideológica incide sobre o conhecimento do mundo do jogo alterando, inclusive as relações que os jogadores estabelecem com ele. É importante destacar que, com essa afirmação, não queremos dizer que os jogadores estejam à mercê das enunciações do jogo: o paradigma inscrito nas imagens e textos pode ser contrainterpretado e desafiado. No entanto, como qualquer movimento de contra-hegemonia, o primeiro passo é o reconhecimento dos valores dominantes. Por esse motivo, consideramos os jogadores mais parecidos com turistas acompanhados por um guia que direciona sua atenção do que com exploradores: por mais pessoais que sejam, suas geografias de ação e suas histórias espaciais nascem sob influência dos filtros inscritos nos modos de enunciação.

As imagens do "cartógrafo a passeio" e do turista que acompanha o guia têm a vantagem adicional de não perderem de vista a interdependência entre mapeamento e 
percurso que, já em de Certeau, aparecem entrelaçados na composição das "geografias de ação". Por outro lado, reconhecemos que sua instrumentalização como categorias analíticas distintas promoveu avanços em estudos empíricos de autores que nos precederam. Quando aplicadas à análise de jogos de estratégia e jogos locativos, as noções de mapeamento e percurso conduziram recorrentemente à conclusão de que sua presença em interfaces digitais promove a hibridação do mapeamento e do turismo, restabelecendo o antigo hibridismo, que teria sido desmantelado pela Modernidade (LAMMES, 2009, 2016; LAMMES; VERHOEFF, 2008; LAMMES; WILMOTT, 2016, 2018). Entendemos, no entanto, que essa separação de fato nunca chegou realmente a acontecer e que os jogos não promovem a interdependência entre os dois tipos de apreensão espacial, apenas a tornam mais visível e fácil de perceber.

\section{Conclusão}

Neste artigo, discutimos como as diferentes formas de representação visual do espaço interferem na relação entre os jogadores e os mundos de jogo. Para isso, tomamos como foco duas estratégias de enunciação: mapas e projeções perspectivadas. Partimos do reconhecimento de que toda imagem é uma construção cultural e, portanto, não reflete de forma precisa e ingênua aquilo que representa. A partir da constatação dos pontos comuns entre os mapas e as imagens em perspectiva, recuperamos o trajeto histórico de sua separação em categorias distintas. Identificamos que essa separação ocorre na passagem para a Modernidade e reflete os muitos dualismos característicos do pensamento daquele período. Ao longo do processo de distinção entre mapas e perspectiva, identificamos o uso de formas transitórias, sobretudo na cartografia. Entre essas, destacamos as projeções oblíquas e mapas ilustrados.

A seguir, discutimos especificidades das imagens sobre as quais situamos nossa problematização. Como parte de jogos digitais, elas são modelos de natureza abstrata, sem correspondente material no mundo físico. Além disso, são imagens com as quais o jogador deve poder interagir. Notamos analogias diretas entre as aplicações de mapas em jogos e no uso cotidiano, cuja base é a suposta correspondência entre as enunciações perspectivadas do mundo do jogo e a visão humana. Assim, tanto no jogo quanto no cotidiano, os mapas são tomados como representações a serem cotejadas com a realidade. Já as imagens em perspectiva têm sua artificialidade reconhecida quando encontradas no dia a dia (em fotografias, ou na televisão, por exemplo), mas não nos jogos. Isso porque, devido à ausência de referente material, apesar de 
sua artificialidade, a enunciação perspectivada ainda é a experiência do mundo do jogo mais direta possível.

Por outro lado, as imagens em perspectiva presentes em jogos podem ser controladas em níveis que não ocorrem em outros meios audiovisuais, o que retira o jogador da posição de observador para situá-lo como um explorador do espaço do mundo de jogo. Essa diferença propicia uma experiência espacial peculiar, na qual identificamos paralelos com práticas espaciais cotidianas. No entanto, cabe ressaltar o peso da mediação da perspectivação, carregada de princípios, valores e crenças modernas cuja inscrição é estrutural e, portanto, nem sempre perceptível ao usuário.

Problematizamos essa percepção a partir do dualismo entre mapeamento e percurso encontrado na literatura anterior sobre a espacialidade em games, assinalando nossas concordâncias e discordâncias com as colocações dos autores que nos precederam. Com isso, verificamos um paralelo entre a natureza híbrida das geografias de ação e a ocorrência combinada de mapas e imagens em perspectiva em games, o que nos levou à constatação de que a experiência espacial dos games resgata o hibridismo das práticas espaciais, superando os limites artificiais dos dualismos criados na Modernidade.

\section{Referências}

AARSETH, E. Allegories of space: the question of spatiality in computer games. [S. l.: s. n.], 1998.

BORGES, J. L. "Do rigor na Ciência”. In: BORGES, J. L. Jorge Luis Borges: obras completas. Rio de Janeiro: Globo, 1999. p. 247.

CALLEJA, G. In-game: from immersion to incorporation. Cambridge, MA: MIT Press, 2011

COUCHOT, E. "Da representação à simulação”. In: PARENTE, A. Imagemmáquina: a era das tecnologias do virtual. Rio de Janeiro: Editora 34, 1993. p. 37-48.

DE CERTEAU, M. Invenção do cotidiano: v. 1: artes de fazer. 3. ed. Petrópolis: Vozes, 1998.

DODGE, M.; KITCHIN, R.; PERKINS, C. Rethinking maps: new frontiers in cartographic theory. London: Routledge, 2011.

EGLISTON, B. "Playing across media: exploring transtextuality in Competitive Games and eSports". In: DIGITAL GAMES RESEARCH ASSOCIATION 
CONFERENCE (DIGRA), 15., 2015, Lünenburg. Proceedings [...]. Lünenburg: Digra, 2015. p. 1-17. Disponível em: https://bit.ly/39cWUnq. Acesso em: 21 jan. 2019.

FRAGOSO, S. "Interface design strategies and disruptions of gameplay: notes from a qualitative study with first-person gamers". In: KUROSU, M. (ed.). Human-computer interaction: application and services. New York: Springer, 2014. p. 593-603.

FRAGOSO, S. O espaço em perspectiva. Rio de Janeiro: E-Papers, 2005.

FRAGOSO, S. "Calidoscopia midiática: da criação à ressignificação das imagens em perspectiva". Intexto, Porto Alegre, n. 11, p. 1-13, 2004. Disponível em: https://seer.ufrgs.br/intexto/article/view/4049. Acesso em: 30 jul. 2020.

FRAGOSO, S. "Perspectivas: uma confrontação entre as representações perspectivadas, o conhecimento científico acerca do espaço e a percepção cotidiana”. Galáxia, São Paulo, v. 14, n. 6, p. 105-120, 2003. Disponível em: https://revistas.pucsp.br/galaxia/article/view/1337. Acesso em: 30 jul. 2020.

FRAGOSO, S. O imaginário digital: considerações sobre as premissas básicas da modelagem geométrica computadorizada. 1992. Dissertação (Mestrado em Comunicação e Semiótica) - Pontifícia Universidade Católica de São Paulo, São Paulo, 1992.

FRAGOSO, S.; AMARO, M. Introdução aos estudos dos jogos. Salvador: Edufba, 2018.

FRIEDMAN, T. "Civilization and its discontents: simulation, subjectivity, and space". In: SMITH, G. M. On a silver platter: CD-ROMs and the promises of a new technology. New York: New York University Press, 1998. p. 132-150.

GOLDING, D. "To configure or to navigate? On textual frames". In: WAGGONER, Z. Terms of play: essays on words that matter in videogame theory. Jefferson: McFarland, 2013. p. 28-46.

HARLEY, J. B. "Deconstructing the Map". Cartographica: The International Journal for Geographic Information and Geovisualization, Toronto, v. 26, n. 2, p. 1-20, 1989.

JØRGENSEN, K. Gameworld interfaces. Cambridge, MA: MIT Press, 2013.

KING, G.; KRZYWINSKA, T. "Computer Games/Cinema/Interfaces". In: COMPUTER GAMES AND DIGITAL CULTURES CONFERENCE, 2002, Tampere, Finland. Proceedings [...]. Tampere, Finland: Tampere University Press, 2002. p. 140-153. 
KORZYBSKI, A. Science and sanity: an introduction to non-aristotelian systems and general semantics. Chicago: Institute of General Semantics, 1958.

LAMMES, S. "Digital mapping interfaces: from immutable mobiles to mutable images". New Media \& Society, Thousand Oaks, v. 19, n. 7, p. 1019-1033. Disponível em: https://doi.org/10.1177/1461444815625920. Acesso em: 27 jan. 2019.

LAMMES, S. "Spatial regimes of the digital playground: cultural functions of spatial practices in computer games". Space and Culture, Thousand Oaks, v. 11, n. 3, p. 260-272, 2008.

LAMMES, S. “Terra incognita: computer games, cartography and spatial stories”. In: VAN DEN BOOMEN, M. et al. Digital material: tracing new media in everyday life and technology. Amsterdam: Amsterdam University Press, 2009. p. 223-238.

LAMMES, S.; VERHOEFF, N. "Landmarks: navigating spacetime and digital mobility”. In: INTERNATIONAL CONFERENCE OF ISSEI LANGUAGE AND THE SCIENTIFIC IMAGINATION, 11., 2008, Helsinki, Finland. Proceedings [...]. Helsinki, Finland: University of Helsink, 2008. p. 1-21. Disponível em: https://bit.ly/3130m6o. Acesso em: 26 jan. 2019.

LAMMES, S.; WILMOTT, C. "Mapping the city, playing the city: Location-based apps as navigational interfaces". Convergence, Thousand Oaks, 2016. Disponível em: https://bit.ly/3nVd9dg. Acesso em: 27 jan. 2019.

LAMMES, S.; WILMOTT, C. “The map as playground: location-based games as cartographical practices". Convergence: The International Journal of Research into New Media Technologies, Toronto, v. 24, n. 6, p. 648-665, dez. 2018.

LATOUR, B. Jamais fomos modernos. São Paulo: Editora 34, 1991.

LINDE, C.; LABOV, W. "Spatial networks as a site for the study of language and thought". Language, Washington, DC, v. 51, n. 4, p. 924-939, 1975.

MACHADO, A. A arte do vídeo. São Paulo: Brasiliense, 1990.

MACHADO, A. A ilusão especular: introdução à fotografia. São Paulo: Brasiliense; Rio de Janeiro: Funarte, 1984.

MACHADO, A. Pré-cinemas ๒ pós-cinemas. Campinas: Papirus, 1997.

MACHADO, A. "Apresentação". In: FRAGOSO, S. O espaço em perspectiva. Rio de Janeiro: E-Papers, 2005, p. 5-12. 
NITSCHE, M. Video game spaces: image, play, and structure in 3D worlds. Cambridge, MA: MIT Press, 2008.

NUTI, L. "The perspective plan in the sixteenth century: the invention of a representational language”. The Art Bulletin, New York, v. 76, n. 1, p. 105-128, 1994.

PANOFSKY, E. Perspective as symbolic form. New York: Zone Books, 1997.

QUÉAU, P. “O tempo do Virtual”. In: PARENTE, A. (org.). Imagem-Máquina. Rio de Janeiro: Editora 34, 1993. p. 91-98.

REES, R. "Historical links between cartography and art". Geographical Review, Abingdon, v. 70, n. 1, p. 61-78, 1980.

ROSE-REDWOOD, R. "Introduction: the limits to deconstructing the map". Cartographica: The International Journal for Geographic Information and Geovisualization, Toronto, v. 50, n. 1, p. 1-8, 2015.

SCULLY-BLAKER, R. "A practiced practice: speedrunning through space with de Certeau and Virilio". Games Studies: the International Journal of Computer Game Research, v. 14, n. 1, 2014. Disponível em: https://bit.ly/3pXIKN1. Acesso em: 24 jan. 2019.

THRIFT, N. Spatial formations. London: Sage, 1996.

WEBER, M. The protestant ethic and the spirit of capitalism. Chelmsford: Courier, 2012.

submetido em: 9 abr. 2019 | aprovado em 22 jun. 2020 